\title{
PENGEMBANGAN SISTEM PEMAUNTAUAN HUJAN BERBASIS WEB
}

\author{
Candra Nur Ihsan \\ Pusat Sains dan Teknologi Atmosfir \\ Lembaga Penerbangan dan Antariksa Nasional \\ J1. Dr. Djunjunan no. 133, Pajajaran, Bandung \\ candra.nurihsan9@gmail.com
}

\begin{abstract}
Abstrak
Cuaca di Indonesia memiliki pengaruh yang penting terhadap aktifitas yang akan dilakukan manusia, baik untuk individu maupun kelompok. Pada era teknologi saat ini penerapan sistem pemantauan cuaca perlu dilakukan untuk memberikan antisipasi terhadap kegiatan yang sudah direncanakan dan juga terhadap potensi bencana yang ada, terutama saat cuaca hujan. Di Lembaga Penerbangan dan Antariksa Nasional (LAPAN) membuat teknologi pengamatan hujan berbasis radar kapal, namun sistem yang dibuat hanya dapat memantau satu buah radar. Pengembangan sistem yang dilakukan yaitu dapat memantau multiradar yang sudah dipasang oleh LAPAN dan memunculkan histori data serta curah hujan pada daerah yang ingin diamati.
\end{abstract}

Kata Kunci:

Sistem, Pengamatan, Hujan, Radar

\begin{abstract}
The weather in Indonesia has an important influence on the activities that humans will carry out, both for individuals and groups. In the current technological era the application of a weather monitoring system needs to be carried out to provide anticipation to planned activities and also to the potential for existing disasters, especially during rainy weather. At the National Aeronautics and Space Agency (LAPAN) makes rain radar technology based on ship's radar, but the system that is made can only monitor one radar. The system development that is carried out is to be able to monitor multi-radars that have been installed by LAPAN and bring up historical data and rainfall in the area of interest to be observed.
\end{abstract}

Keywords :

Systems, Observations, Rain, Radar

\section{Pendahuluan}

Indonesia merupakan Negara Kepulauan yang memiliki 2 Musim, yaitu Musim Panas dan Musim Hujan. Indonesia memiliki kadar curah hujan yang cukup tinggi, yakni berkisar antara $2.000-3.000 \mathrm{~mm}$ setiap tahunnya. Keadaan tersebut membuat masyarakat di Indonesia harus memiliki antisipasi yang lebih, terutama saat memasuki Musim Hujan agar aktifitas yang sudah direncanakan berjalan dengan baik.

Di Lembaga Penerbangan dan Antariksa Nasional (LAPAN) sudah memiliki Sistem Pemantauan Hujan (SANTANU). Sistem tersebut dapat memantau hujan di Bandung berdasarkan data yang diperoleh dari radar yang sudah dipasang oleh LAPAN. Dengan adanya sistem tersebut, kini masyarakat di Kota Bandung dapat menantisipasi terjadinya banjir yang mungkin terjadi saat hujan tiba (Ginaldi Ari Nugroho dan Tiin Sinatra, 2018).

Permasalahan yang terjadi adalah Sistem Pemantauan Hujan yang sudah dibuat oleh LAPAN belum memiliki wadah untuk melakukan integrasi untuk multi-radar, sehingga data yang ditampilkan hanya fokus pada satu radar yang sudah dipasang. Selain itu, data visual yang disajikan pada SANTANU belum optimal, tidak ada histori kondisi curah hujan yang sudah turun di Kota Bandung sebagai bahan evaluasi lebih lanjut.

Multi-radar yang sudah di sebar berfungsi untuk memantau cuaca di wilayah tertentu sesuai dengan penimpanan radar dengan jarak pembaacaan data dari radar adalah $44 \mathrm{~km}$. 
Berdasarkan permasalahan yang sudah dipaparkan, peneliti bertujuan untuk mengembangkan Sistem Pemantau Hujan Berbasis WEB yang mampu menampilkan visualisasi data multi radar dengan baik. Penyajian histori curah hujan pada daerah yang dikehendaki disajikan dalam bentuk grafik sehingga pengguna dapat melakukan evaluasi lebih lanjut.

\section{KAJIAN LITERATUR}

\section{II.1 Sistem}

Sistem adalah kumpulan /group dari sub sistem / bagian / komponen apapun baik phisik maupun non phisik yang saling berhubungan satu sama lain dan bekerja sama secara harmonis untuk mencapai satu tujuan tertentu (Andi Kristanto, 2008).

\section{II.2 Cuaca}

Cuaca adalah keadaan atmosfer pada setiap waktu kesatuan. Dengan demikian kita dapat mengatakan cuaca besok pagi, cuaca minggu ini, cuaca minggu depan, cuaca bulan depan, dan seterusnya apabila waktu-waktu tersebut diartikan sebagai satu satuan waktu. Jadi cuaca menyatakan keadaan yang berlangsung pada saat atau selama waktu kesatuan (Soerjadi and Swarinoto, 2010).

Kelembaban dan suhu udara selalu berubah setiap waktu. Intensitas cahaya yang diteruskan ke permukaan bumi setelah melalui lapisan atmosfir akan selalu berubah, menyesuaikan dengan keadaan dan ketebalan awan. Hal serupa juga dialami oleh penentuan kecepatan arah angin. Kondisi atmosfir yang dinamis, berubah dalam waktu singkat (dalam jam atau hari) disebut cuaca (Lakitan, 2002).

\section{II.3 Hujan}

Hujan merupakan salah satu unsur cuaca yang penting karena jumlah hujan yang diterima oleh suatu wilayah sangat menentukan kondisi sumberdaya air di wilayah tersebut. Dalam hal ini hujan menunjukan variasi ruang dan waktu, artinya bahwa jumlah hujan beragam dari suatu tempat ke tempat lain dan dari satu waktu ke waktu yang lain. Variasi ini terkait mekanisme dan proses kejadian pembentukan hujan yang memerlukan sedikitnya 3 hal (Sumner, 1988), yaitu :

1. Jumlah lengas udara yang cukup
2. Adanya proses pendinginan untuk terjadinya proses kondensasi

3. Jumlah nukleus kondensasi yang cukup

Menurut Kartasapoetra (2004), hujan merupakan salah satu bentuk presipitasi uap air berasal dari awan yang terdapat di atmosfir. Bentuk presipitasi lainnya adalah salju dan es. Untuk dapat terjadinya hujan diperlukan titik-titik kondensasi, amoniak, debu, dan asam belerang. Titik-titik kondensasi ini mempunyai sifat dapat mengambil uap air dari udara. Jumlah curah hujan dicatat dalam inci atau millimeter (1inci $=$ $25.4 \mathrm{~mm}$ ). Jumlah curah hujan $1 \mathrm{~mm}$ menunjukkan tinggi air hujan yang menutupi permukaan $1 \mathrm{~mm}$, jika air tersebut tidak meresap ke dalam tanah atau menguap ke atmosfir (Tjasjono, 2004).

\section{3 Rapid Aplication Development}

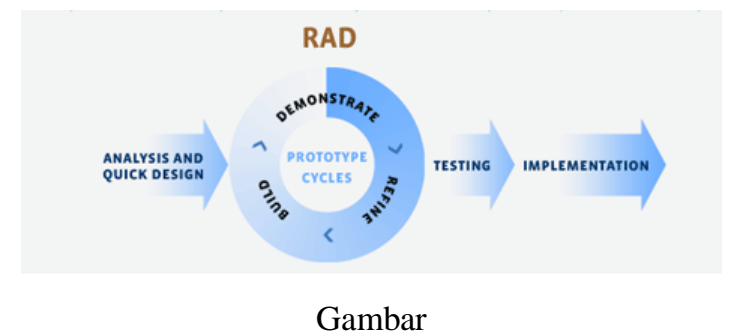

Penerapan metode RAD dalam untuk mengembangkan sistem pemantauan hujan melalui sejumlah tahapan, yang diawali dengan tahap analisis sistem yang sudah berjalan, melibatkan pengguna dan engineer untuk merancang dan membangun sistem (kegiatan ini dilakukan secara berulang-ulang hingga mencapai kesepakatan bersama), dan terakhir tahap implementasi. Tahapan perencanaan menjadi syarat kebutuhan sistem pemantau cuaca hujan berhubungan dengan pengumpulan semua data/informasi pengguna.Aktifitas tersebut memeriksa kesesuaian untuk konsistensi dan kelengkapan data dalam pengembangan sistem. Pengumpulan data dilakukan dengan melakukan wawancara kepada engineer sebelumnya, observasi data dan studi dokumen. Pengelompokan kebutuhan dilakukan untuk pemahaman data yang lebih mudah, Selain itu, kebutuhan fungsional yang berhubungan dengan proses pengamatan perilaku sistem dilakukan untuk memahami tujuan yang akan dicapai.
Candra Nur Ihsan

II.3. Radar 
Radar merupakan singkatan dari Radio Detection and Ranging merupakan perangkat yang berfungsi untuk menghitung jarak, arah atau kecepatan dari objek bergerak dan tetap (Rustamaji and Djaelani, 2012). Radar dapat digunakan untuk aplikasi pemetaan pada ruang lingkup yang tidak diketahui. Radar juga dapat membantu nagvigasi objek bergerak (Estiningtyas, Ramdhani and Aldrian, 2007).

Penggunaan radar pada peta dapat memberikan informasi yang lebih baik untuk memantau suatu aktifitas objek yang akan dilakukan pengamatan.

\section{II.4. Website}

Website atau disingkat web merupakan beberapa laman yang berisi informasi dalam bentuk data digital baik berupa text, gambar, video, audio, dan animasi lainnyayang disediakan melalui jalur internet (Abdulloh, 2016).

\section{Pengembangan}

Pengembangan site dapat dilakukan oleh setiap engineer. Dengan semakin banyaknya engineer kebutuhan informasi berbasis web sudah semakin meningkat. Sajian informasi yang secara praktis dapat didapatkan oleh masyarakat dengan mudah. Website berbasis dinamis sudah banyak diminati oleh masyarakat karena website yang dinamis memiliki kelebihan isi konten dapat berubah mengikuti isi dari basis data. Seseorang tidak perlu mengganti pemrograman website melainkan cukup melakukan update data ke dalam basis data(Rahman, 2013).

\section{ANALISIS DAN PERANCANGAN}

\section{1. Metodologi Penelitian}

Metodologi Pengembangan Sistem yang dilakukan yaitu menggunakan metode RAD (Rapid Aplication Development. Proses-proses yang dilakukan dengan RAD dapat dilihat pada Gambar 3.1.

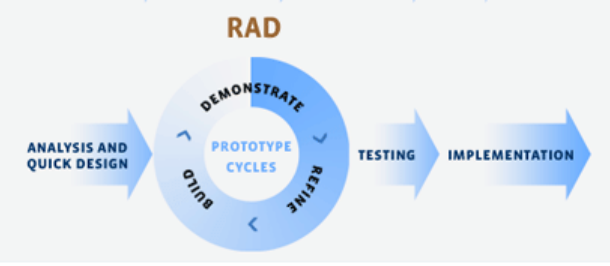

Gambar 3.1. Model Rapid Aplication Development
(Sumber: researchgate.net)

Tahapan RAD yang dilakukan untuk mengembangkan Sistem Pemantauan Hujan (SANTANU) adalah:

1. Analisis

Analisis yang dilakukan dari data yang sudah didapatkan dari Engineer sebelumnya yang membangun SANTAU yakni:

a. Sampling Radar dilakukan setiap 2 menit

b. Data memiliki dimensi matriks sebesar $734 \times 734$

c. Jangkauan radar sekitar $44 \mathrm{~km}$.

2. Desain

Perancangan pengembangan sistem yang dilakukan yaitu menggunakan Unified Modelling Language (UML). Sistem dirancang untuk memenuhi kebutuhan pengguna, yaitu melihat data cuaca dengan multi radar.

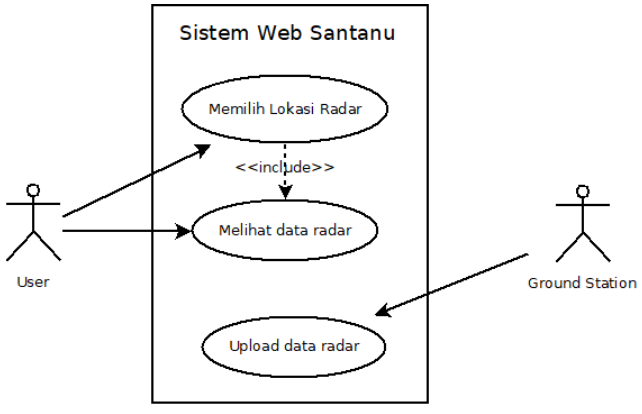

Gambar 3.2. Use Case Diagram

Selain perancangan sistem, perancangan basis data juga dilakukan agar sistem dapat mendukung pembacaan data dari multi-radar. Perancangan basis data dapat dilihat pada Gambar 3.3.
Candra Nur Ihsan

Jurnal Ilmiah Teknologi Informasi Terapan

Volume 6, No 1, 15 Desember 2019 


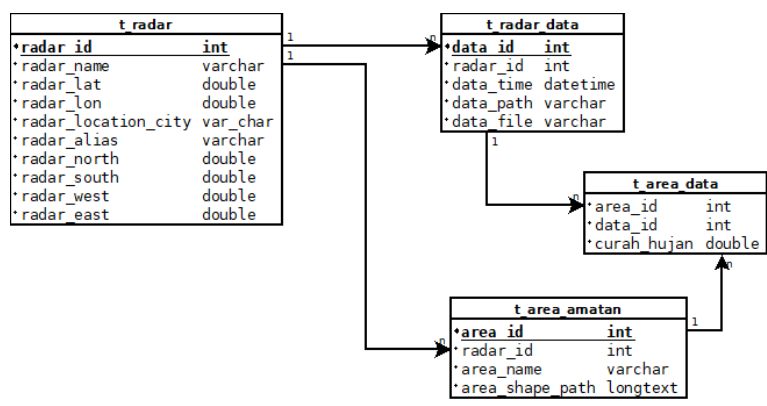

Gambar 3.3. Perancangan Basis Data

3. Build

Sistem Pemantau Hujan yang dikembangkan yaitu berbasis website dengan bahasa pemrograman phyton dengan basis framework flask dan untuk basis data menggunakan MariaDB.

4. Refine

Refine dilakukan sebelum melakukan tahap implementasi Sistem Pemantau Hujan yang sudah dikembangkan. Setelah versi beta di diuji pada engineer Sistem Pemantau Hujan sebelumnya mengenai tampilan web diantaranya adalah:

a. Penyesuaian warna dan range data sesuai dengan data radar BMKG.

b. Penambahan bagian untuk melihat data history selama 1 jam ke belakang.

c. Penambahan daerah amatan hujan untuk mengetahui curah hujan di daerah yang di kehendaki.

d. Penambahan halaman versi mobile devices.

\section{3. Implementasi Sistem}

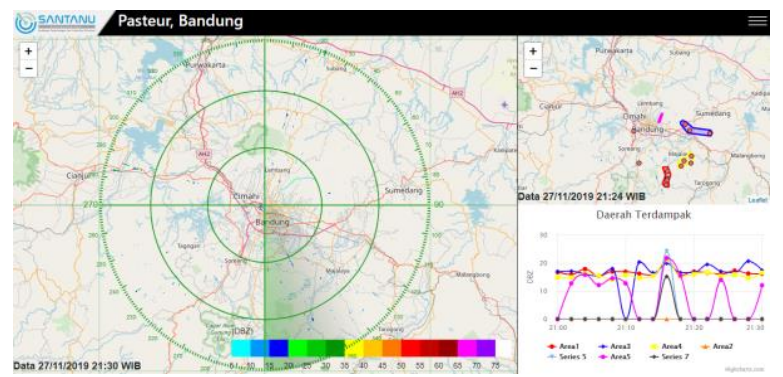

Gambar 3.4. Halaman Utama SANTANU
Halaman default user akan dipilihkan lokasi radar di Pasteur, Bandung (-6.894941 , 107.58648) yang merupakan lokasi kantor Pusat Sains dan Teknologi Atmosfer, halaman terdiri dari tiga segmen, yaitu tampilan data terkini (sebelah kiri), tampilan history (atas kanan) dan tampilan daerah amatan (grafik kanan bawah).

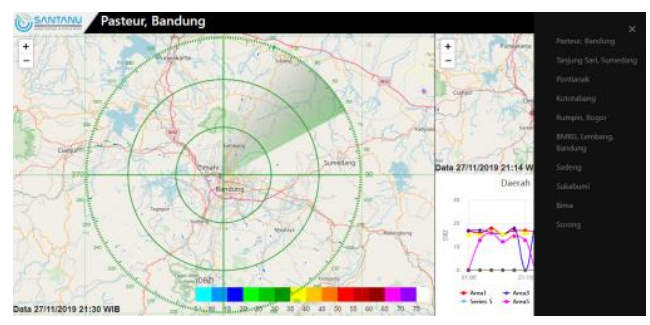

Gambar 3.5. Menu Navigasi SANTANU

Menu navugasi SANTANU berfungsi untuk memilih radar yang sudah dipasang oleh LAPAN.Menu ini merupakan pengembangan dari sistem yang sebelumnya, sehingga memudahkan pengguna untuk memilih posisi radar yang sudah dipasang.

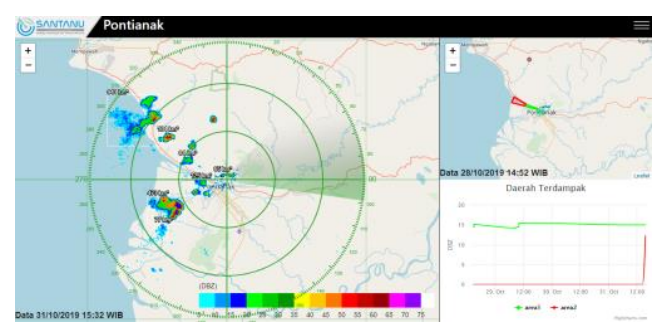

Gambar 3.6. Halaman Radar Pontianak

Contoh pengamtan radar yang berlokasi di Pontianak (-0.003386, 109,367566).

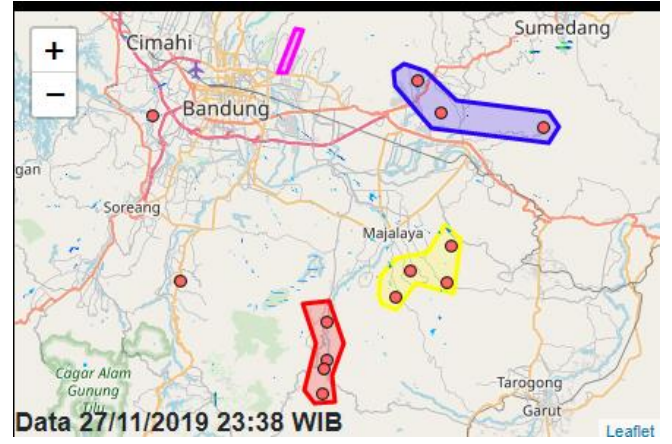

Gambar 3.7. Daerah Terdampak Hujan

Daerah terdampak ini menampilkan daerah yang curah hujannya diamati dan masuk ke dalam grafik.
Candra Nur Ihsan

Jurnal Ilmiah Teknologi Informasi Terapan

Volume 6, No 1, 15 Desember 2019 


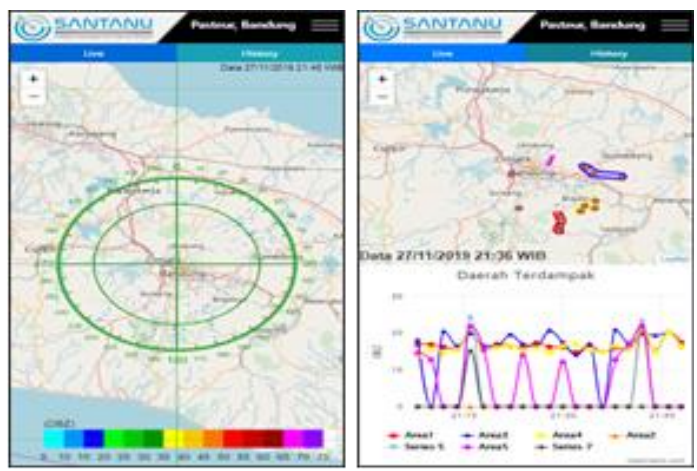

Gambar 3.8. Tampilan pada mobile devices

Tampilan versi mobile devices terdiri dari dua bagian, bagian data live dan bagian data history yang di kontrol menggunakan tombol diatas (live, history).

\section{4. Pengujian Pengembangan SANTANU}

Pengujian Pengembangan SANTANU dilakukan menggunakan pengujian Blackbox. Hasil Pengujian dapat dilihat pada tabel 1.

Tabel 1 Hasil Pengujian

\begin{tabular}{|c|c|c|c|}
\hline No & $\begin{array}{l}\text { Skenario } \\
\text { Pengujian }\end{array}$ & $\begin{array}{l}\text { Hasil Yang } \\
\text { Diharapkan }\end{array}$ & Kesimpulan \\
\hline 1 & $\begin{array}{l}\text { Memuat halaman } \\
\text { utama }\end{array}$ & $\begin{array}{ll}\text { Muncul } & \text { Data } \\
\text { Radar } & \end{array}$ & Valid \\
\hline 2 & Memuat Histori & $\begin{array}{ll}\text { Muncul Histori } \\
\text { Hujan Berupa } \\
\text { Grafik }\end{array}$ & Valid \\
\hline 3 & Memilih Lokasi & $\begin{array}{lr}\text { Memuat } & \text { Lokasi } \\
\text { sesuai } & \text { yang } \\
\text { dipilih } & \end{array}$ & Valid \\
\hline 4 & Memuat Peta & $\begin{array}{l}\text { Terhubung } \\
\text { dengan Leaflet } \\
\text { dan } \\
\text { menampilkan } \\
\text { peta }\end{array}$ & Valid \\
\hline 5 & $\begin{array}{l}\text { Menampilkan } \\
\text { Semua Radar }\end{array}$ & $\begin{array}{ll}\text { Memuat } & \text { data } \\
\text { cuaca } & \text { pada } \\
\text { radar } & \text { yang } \\
\text { dipilih } & \end{array}$ & Valid \\
\hline 6 & $\begin{array}{l}\text { Menampilkan } \\
\text { Halaman } \\
\text { Terdampak }\end{array}$ & $\begin{array}{l}\text { Memuat } \\
\text { Halaman } \\
\text { Terdampak } \\
\text { sesuai dengan } \\
\text { lokasi yang } \\
\text { dipilih }\end{array}$ & Valid \\
\hline
\end{tabular}

\section{KESIMPULAN DAN SARAN}

Berdasarkan hasil penelitian yang penulis lakukan, dapat disimpulkan bahwa:

1. Sistem pengamatan hujan berbasis web berhasil dikembangkan sebagai bagian dari sistem santani yang di kembangakan oleh pusat sains dan teknolgi atmosfer LAPAN.

2. Sistem yang dikembangkan mampu menampilkan visualisasi data dari berbagai radar yang diamati oleh PSTA, serta mampu menampilkan data curah hujan di daerah yang ingin diamati

\section{REFERENSI}

Abdulloh, R. (2016) Easy dan Simple Web Programming. Jakarta: Elex Media Komputindo.

Aksara, Jakarta.,S. (2013) Cara Gampang Bikin CMS PHP Tanpa Ngoding. Jakarta: PT TransMedia.

Andi Kristanto. 2008. Perancangan Sistem Informasi. Gava Media. Yogyakarta

Estiningtyas, W., Ramdhani, F. and Aldrian, E. (2007) 'Analisis Korelasi Curah Hujan Dan Suhu Permukaan Laut Wilayah Indonesia, Serta Implikasinya Untuk Prakiraan Curah Hujan (Studi Kasus Kabupaten Cilacap)', J. Agromet Indonesia, 21(September), pp. 46$60 . \quad$ Available at: http://journal.ipb.ac.id/index.php/agromet/art icle/viewFile/3479/2379.

Ginaldi Ari Nugroho and Tïn Sinatra (2018) Sistem Pemantauan Hujan (SANTANU). Bandung: Antasena.

Lakitan, B., 2002. Dasar-dasar Klimatologi. PT Raja Grafindo Persada, Jakarta.

RahmanKartasapoetra, A.G., 2004. Klimatologi Pengaruh Iklim terhadap Tanah dan Tanaman. PT Bumi

Rustamaji and Djaelani (2012) 'Radar Jamming Suatu Konsep Rancang Bangun', Jurnal Electrans, II(2), pp. 71-80. 
Soerjadi, W. and Swarinoto, Y. (2010) Iklim Kawasan Indonesia (Dari Aspek Dinamik - Sinoptik). doi: 10.1016/j.ejop.2005.06.002

Sumner, G. 1988. Precipitation, Process and Analysis, Jhon Wiley and Sons, Great Britain

Tjasjono, B., 2004. Klimatologi. ITB, Bandung. 